\title{
Analysis and Evaluation of Overseas Students' Logistic Life Satisfaction - A Case Study of Nanjing University of Science and Technology
}

\author{
Samal Ushan ${ }^{1}$ and Yifei Tong ${ }^{2}$ \\ ${ }^{1}$ Nanjing University of Science and Technology, Nanjing, P.R China \\ ${ }^{2}$ Nanjing University of Science and Technology, Nanjing, P.R China \\ 1samal.ushan@mail.ru
}

Keywords: Overseas students in China; Logistics; Questionnaire survey

\begin{abstract}
To select the overseas students from Nanjing University of Science and Technology as the subjects of the survey, and conduct a questionnaire survey on the living satisfaction of the overseas students in China in the form of logistics. By collecting the relevant attributes of overseas students from Nanjing University of Science and Technology and using SPSS 19.00 software for alpha reliability analysis, to get an objective comprehensive evaluation of satisfaction. The research provides empirical data and policy recommendations for promoting the further development education of overseas students coming to China in Nanjing University of Science and Technology.
\end{abstract}

\section{Introduction}

With the development of China's economy and the enhancement of comprehensive national strength in recent years, China has also become an important country of study abroad, and the number of overseas students in China has rapidly increased. According to statistics, the total number of overseas students in China at the end of 2013 has exceeded 350,000, involving as many as 203 countries. China ranks third after the United States and the United kingdom in terms of the number of overseas students, and that number continues to grow. This figure is expected to reach $500,000^{[1]}$ by 2020 . Life satisfaction of overseas students is not only an expression form of internationalization of higher education, but also an important part of colleges and universities management. As the best propagandist of the school, overseas students determine the reputation and word of mouth of the school. Therefore, colleges and universities are faced with the problem of how to optimize management, provide high-quality services to attract overseas students, so that schools have a foothold in the fierce competition.

\section{Status Quo at Home and Abroad}

The term “顾客满意” is translated from Customer Satisfaction (CS). Since the American scholar Cardozo first discussed customer satisfaction in $1965^{[2]}$, a large number of scholars have conducted a lot of discussion and research on the meaning of customer satisfaction and customer satisfaction degree, as well as measurement methods and analysis model of customer satisfaction degree. In recent years, with the increasing popularity of studying abroad, domestic and foreign universities pay more att ention to the level of overseas students satisfaction degree. At the same time, the research on the satisfaction degree of overseas students has gradually become a hot research topic in colleges and universities. How to improve the logistics life satisfaction of overseas students? Domestic and foreign scholars used different methods to analyze the satisfaction factors, established a reasonable satisfaction evaluation model, and gave the appropriate optimization scheme. For the analysis of satisfaction degree factors, domestic and foreign scholars have carried out a large number of analysis and research. Using questionnaires, Nerguz Bulut Serin ${ }^{[3]}$ conducted a survey of 348 students of different majors during 2008-2009 in Cyprus International University, and by means of the SPSS 11 data analysis software, studied the function relationship between anxiety and depression degrees, gender, socioeconomic level, apartment satisfaction degree, patent education level and life satisfaction degree. Stepwise regression analysis was used to analyze the data. The 
results showed that anxiety, depression, accommodation satisfaction, social economic level and other factors significantly affected life satisfaction. Nazmiye Civitci ${ }^{[4]}$ studied the change of social comparison mentality of Turkish undergraduate students, and the influence of students' willpower on life satisfaction; secondly, studied the moderating effect of social comparison mentality on the relationship between students' willpower and life satisfaction. A total of 326 undergraduates were investigated by multivariate covariance analysis. The results showed that undergraduates with low social awareness of comparison had higher willpower and life satisfaction than those with high social awareness of comparison.

Muhammad Hilmy Muslim ${ }^{[5]}$ from Malaysia studied the satisfaction degrees of living environment of in-school and out-of-school accommodations in the form of concept summary. Using qualitative and quantitative analysis methods, he summarized and collated the research papers on life satisfaction from 1997 to 2012, and gave the main factors that affect life satisfaction degree of living environment such as students' living conditions, students' social activities, community facilities and services, nearby physical environment, living costs and students' preferences, etc.. In the 1990s, Wang Xiaobing and Hu Qingqing ${ }^{[6]}$ began to study the quality of higher education service abroad, and accumulated a large number of successful experience of student satisfaction degree evaluation. The systematic study on higher education service quality in China began with the publication of Liu Junxue's The Theory of Service Quality of Higher Education. Since then, a large number of literature had emerged to explore the concept and theory of higher education service quality, and the satisfaction evaluation of domestic college students had been carried out from the practical level, and to evaluate the degree of satisfaction of college students in China from the practical aspect. Generally speaking, there were more theoretical analysis on the service quality and student satisfaction degree of higher education in China, most of which were based on the model. But the empirical research was relatively few, and mainly on the evaluation of the service quality and student satisfaction of a certain type of colleges and universities, which lacked of analysis of the problems existing in the service and the corresponding improvement strategy research. Due to the lack of analysis on the service process of higher education, in terms of higher education, the theory of service quality model borrowed from enterprises has the suspicion of being hard to adapt, and lack of corresponding revision to the particularity of higher education service. In order to improve the logistics management and service level of overseas students in Nanjing university of technology, promote the development of the cause of overseas students in Nanjing university of technology, open up the education market for overseas students, to achieve an important indicator of internationalization of colleges and universities, this project carries out the investigation and research on overseas students satisfaction degree to the logistics life of colleges and universities, which was of great significance to the overseas students enrollment and the improvement of the quality of satisfaction degree in the future.

\section{Data Collection}

The study was conducted at Nanjing University of Science and Technology from March 2017 to May 2017. There were a total of 823 overseas students who responded to the issued questionnaire. The design of this questionnaire included two sections: the basic situation and the life satisfaction degree of overseas students, which were divided into three parts and 42 questions. The first part was to understand the basic situation of overseas students in China, including the subject's gender, nationality, Chinese or not, age, education level, located medical school, learning type, tuition source, time of arrival, Chinese language learning level and the purpose of learning in Nanjing. The second part and the third part were the main body of the questionnaire, which investigated the oversea students living adaptation in Nanjing mainly from language, life, psychology and culture four aspects. The second part used the form of the five metric table, and the evaluation from 1 5 was: extremely dissatisfied to extremely satisfied. The third part adopted the form of a combination of single choice and multi-choice to investigate the specific performance of overseas students in Nanjing. Considering the Chinese level of some overseas students, the questionnaire was available in both Chinese and English versions, 750 questionnaires were distributed, 635 questionnaires were 
collected, the recovery rate were $84 \%$, of which 619 were valid, the effective rate was $82 \%$. A total of 619 valid questionnaires were collected, of which 336 were male, accounting for $54.3 \%$ of the total sample; 283 were women, accounting for $45.7 \%$ of the total sample; 70 were doctors, accounting for $11.3 \%$ of the total sample; 180 were graduate students, accounting for $29.1 \%$ of the total sample; 309 were undergraduates, accounting for $59.7 \%$ of the total sample, and 60 people studied Chinese, accounting for 9.8\% of the total sample; 111 people were aged between 15-20 years old, accounting for $17.9 \%$ of the total sample; 347 people were aged between $21-25$ years old, accounting for $56.1 \%$ of the total sample; 118 people were aged between 26-30 years old, accounting for $19.1 \%$ of the total sample; 41 people were aged between $31-35$, accounting for $6.6 \%$ of the total sample; 3 people were more than 35-year-old, accounting for $3 \%$ of the total sample; 497 people were Moslems, accounting for $80.3 \%$ of the total sample; 61 people were Christians, accounting for $9.9 \%$ of the total sample; 31 people were Buddhists, accounting for $5 \%$ of the total sample; 14 people were atheists, accounting for $23 \%$ of the total; 16 people had other religions, accounting for $2.6 \%$ of the total sample; 30 people had very good Chinese level, accounting for $4.8 \%$ of the total sample; 175 people had good Chinese level, accounting for $28.3 \%$ of the total sample; 273 people had general Chinese level, accounting for $44.1 \%$ of the total sample; and 141 people's Chinese levels were not good, accounting for $22.8 \%$ of the total sample.

Table 3.1 The data were obtained from School of International Education according to the number of overseas students in 2017 by continents and reports of their academic learning status

(These were the data before the questionnaire survey)

\begin{tabular}{|c|c|c|c|c|c|c|c|c|c|c|c|}
\hline $\begin{array}{c}\text { Serial } \\
\text { number }\end{array}$ & & Long-term & & & & & & & $\begin{array}{c}\text { Subtotal } \\
\text { of long- } \\
\text { term } \\
\text { students }\end{array}$ & $\begin{array}{l}\text { Subtotal } \\
\text { of } \\
\text { short- } \\
\text { term } \\
\text { students }\end{array}$ & \\
\hline & Scholars & $\begin{array}{c}\text { Preparatory } \\
\text { courses } \\
\text { Chinese } \\
\text { advance }\end{array}$ & $\begin{array}{l}\text { General } \\
\text { advance }\end{array}$ & $\begin{array}{l}\text { High } \\
\text { advance }\end{array}$ & $\begin{array}{l}\text { Junior } \\
\text { college }\end{array}$ & $\begin{array}{l}\text { Under- } \\
\text { graduate }\end{array}$ & $\begin{array}{l}\text { Master } \\
\text { research }\end{array}$ & $\begin{array}{l}\text { Doctor } \\
\text { research }\end{array}$ & & & Total \\
\hline $\begin{array}{l}\text { Subtotal } \\
\text { of Asia }\end{array}$ & 0 & $14 \quad 26$ & 0 & 0 & 0 & 344 & 171 & 65 & 620 & 0 & 620 \\
\hline $\begin{array}{l}\text { Subtotal } \\
\text { of South } \\
\text { America }\end{array}$ & 0 & $\begin{array}{ll}0 & 0 \\
\end{array}$ & 0 & 0 & 0 & 2 & 1 & 0 & 3 & 0 & 3 \\
\hline $\begin{array}{l}\text { Subtotal } \\
\text { of } \\
\text { Oceania }\end{array}$ & 0 & $\begin{array}{ll}0 & 0 \\
0\end{array}$ & 0 & 0 & 0 & 2 & 0 & 0 & 2 & 0 & 2 \\
\hline $\begin{array}{l}\text { Subtotal } \\
\text { of } \\
\text { Australia }\end{array}$ & 0 & $\begin{array}{ll}0 & 0 \\
\end{array}$ & 0 & 0 & 0 & 9 & 8 & 2 & 23 & 0 & 23 \\
\hline $\begin{array}{l}\text { Subtotal } \\
\text { of Africa }\end{array}$ & 0 & $\begin{array}{ll}0 & 0 \\
0\end{array}$ & 0 & 0 & 0 & 104 & 25 & 32 & 166 & 0 & 166 \\
\hline Total & 0 & $\begin{array}{ll}0 & 0 \\
\end{array}$ & 0 & 0 & 0 & 465 & 207 & 100 & 823 & 0 & 823 \\
\hline
\end{tabular}


Table 3.2 Data Divided by Majors in Samples

\begin{tabular}{|c|c|c|c|c|c|c|c|c|}
\hline Major & Engineering & $\begin{array}{c}\text { Literatur } \\
\mathrm{e}\end{array}$ & Pedagogy & Law & $\begin{array}{c}\text { Neo- } \\
\text { Confucianism }\end{array}$ & $\begin{array}{c}\text { Managemen } \\
\mathrm{t}\end{array}$ & $\begin{array}{c}\text { Economic } \\
\mathrm{s}\end{array}$ & Total \\
\hline & 446 & 54 & 1 & 10 & 65 & 75 & 172 & 823 \\
\cline { 2 - 8 } & $54 \%$ & $5.6 \%$ & $0.1 \%$ & $1.2 \%$ & $7.89 \%$ & $9.11 \%$ & $20.89 \%$ & $100 \%$ \\
\hline
\end{tabular}

According to the analysis of majors, $54 \%$ of overseas students in Nanjing University of Science and Technology chose engineering major. Because of the rapid development of this major in China and the more frequent exchanges and opportunities between China and the rest of the world, many overseas students chose this major to give themselves a better future. At the same time, people who choose economics, management, neo-confucianism and literature were also many, because China's research and development in these professions were faster than other developing countries.

\section{Research and Analysis}

\section{Reliability Analysis}

Reliability, also known as credibility, refers to the degree of reliability of the questionnaire, which mainly shows the consistency, conformity, reproducibility and stability of the test results. The commonly used methods are retest reliability method, duplicate reliability method and Cronbach $\alpha$ reliability coefficient method. Retest reliability method is to use the same questionnaire to retest the same group of respondents at regular intervals and calculate the correlation coefficients between the results of the two tests. Because the retest reliability method needs to test the same sample twice, the respondents are easily affected by various events, activities and other people, the length of the interval is also limited, the most important thing is that the questionnaire is issued with the help of network platform and not easy to count the specific subjects information, so it is difficult to implement. Therefore, this survey used the variable duplicate reliability method and Cronbach $\alpha$ reliability coefficient method. The standard duplicate reliability method allows the same group of respondents to fill out two copies of the questionnaire at a time, calculating the correlation coefficients of the two duplicates. Because it was not easy to implement, this survey intent to repeat two options. If the respondents had different answers to the same question, they would be regarded as invalid questionnaire ${ }^{[7-9]}$.

The second method was Cronbach $\alpha$ reliability coefficient method. The consistency between the scores of the questions in the scale was an intrinsic consistency coefficient. The formula was as follows ${ }^{[10]}$ :

$$
\alpha=\frac{k}{k-1}\left(1-\frac{\sum s_{i}^{2}}{s_{x}^{2}}\right)
$$

In the formula, $\mathrm{K}$ was the number of test questions, $s_{i}^{2}$ was the variation of the score of a test, $s_{i}^{2}$ was the variation of the total score of the test (wherein $\mathrm{K}$ was the sample, $\sigma 2 \mathrm{X}$ was the variance of the total sample, and $\sigma 2 \mathrm{Yi}$ was the variance of the current observed sample). Get the whole volume $\alpha$ of the questionnaire Total reliability of questionnaire $0.926 \quad \alpha$ reliability coefficient of each sub-volume. The evaluation principle of Cronbach $\alpha$ reliability coefficient method is shown in Table 3.3

Table 3.3 Classification of Importance

\begin{tabular}{|l|c|c|}
\hline Sub-volume & $\alpha$ reliability coefficient & Totalreliability of questionnaire \\
\hline Dormitory satisfaction & 0.861 & \multirow{2}{*}{0.926} \\
\cline { 1 - 2 } Canteen satisfaction & 0.872 & \multirow{2}{*}{0.926} \\
\hline Library satisfaction & 0.988 & \\
\cline { 1 - 2 } International school satisfaction & 0.965 & \\
\cline { 1 - 2 } School hospital satisfaction & 0.909 & \\
\cline { 1 - 2 } Education satisfaction & 0.966 & \\
\hline
\end{tabular}


From the results of the above table, the total reliability of the questionnaire Cronbach $\alpha=0.926$, indicating that the overall internal consistency of the scale was high; and all Cronbach $a$ values were above 0.7 , indicating that the reliability of the scale was good as well as the stability of the questionnaire.

\section{Validity Analysis}

Validity, that is, the validity of the questionnaire. It refers to the validity of the questionnaire, that is, check to see whether the understanding of the content measured by the questionnaire is consistent with the different groups of people or not.

The validity of this paper was tested by KMO sample test. In this case, it could judge whether the model is suitable for factor analysis or not according to KMO value ${ }^{[11]}$.

$\mathrm{KMO}>0.9$, extremely suitable;

$0.9>\mathrm{KMO}>0.8$, very suitable;

$0.8>\mathrm{KMO}>0.7$, suitable;

$0.7>\mathrm{KMO}>0.6$, not very suitable;

$0.6>\mathrm{KMO}>0.5$, barely;

$0.5>\mathrm{KMO}$, not suitable ${ }^{[12]}$.

The results as shown in Table 3.4 could be obtained by enter the data of this survey into software. Table 3.4 Experiences of KMO and Batlett

\begin{tabular}{|c|c|c|}
\hline \multicolumn{2}{|c|}{ Kaiser-Meyer-Olkin measurement sampling suitability } & .814 \\
\hline \multirow{3}{*}{$\begin{array}{c}\text { Spherical identification of } \\
\text { Bartlett }\end{array}$} & About chi-square & 30529.862 \\
\cline { 2 - 3 } & Df & 406 \\
\cline { 2 - 3 } & Sig & .000 \\
\hline
\end{tabular}

It could be found from the above table that the sample was suitable for factor analysis when the KMO value was 0.814 . The significant probability of Bartlett sphere test was 0.000 , indicating that there was a strong correlation between test variables, and the test results were very suitable for factor analysis. After the preliminary test, it was proved that the model of this study was effective. Therefore, the evaluation index system had reference significance. Based on the existing evaluation index system and others, life satisfaction degree of overseas students could be studied ${ }^{[13]}$.

\section{Discussion}

For overseas students at Nanjing University of Science and Technology, many of them are going abroad for the first time, and the customs of China are very different from those of their own country.inthe analysis, life satisfaction degree of overseas students is greatly affected accommodation satisfaction, catering satisfaction, library satisfaction, hospital satisfaction, International School satisfaction, and education satisfaction degrees, coupled with the remote life alone, language communication barriers, resulting in overseas students are difficult to adapt to the new environment, facing great difficulties in learning and life, and some even think of returning home. It can be seen that students' individual social adaptability is the premise of good learning attitude. Only when they adapt to the environment well, it is possible for the overseas students to establish a positive learning attitude. Of course, a positive study attitude, in turn, promotes the students to integrate into their study and life faster. The results of a number of studies have shown that the Chinese proficiency of overseas students can help them to better adapt to study and live in foreign country. Their living standards directly affect their learning satisfaction degree. Therefore, putting forward suggestions on how to improve the bottleneck of overseas students' life is an important measure to attract more students to come to China, which has a profound significance to improve the comprehensive strength of China ${ }^{[14-15]}$. 


\section{Conclusion}

After investigated the logistics life satisfaction degree of overseas students in Nanjing University of Science and Technology and consulted the evaluation data, it is found in the survey: due to the late start of logistics reform in China's colleges and universities, which is also in the continuous development, the society is not fully aware of the logistics improvement in colleges and universities, and college logistics enterprises and general social enterprises are different. On this basis, the college students' logistics life satisfaction degree is measured and evaluated. Through the analysis of the results of the survey, it is found that the overseas students have a fairly low degree of satisfaction for the library of Nanjing University of Science and Technology and the factors of study and life, which has a great influence.

In the process of assessing the life satisfaction degree of overseas students for the logistics of university, through the exchange with the relevant departments of the school, it is confirmed that the evaluation results are consistent with the actual situation and provide a certain basis for their work improvement. It is hoped that through this study, the concept of "university overseas students' logistics life satisfaction degree" can be further promoted to facilitate the concept transformation of college logistics service quality; provide the basis for improving the service work of university logistics service institutions; and facilitate the university logistics enterprises to establish a correct view of university logistics service.

\section{References}

[1] Zhang Xueqiao. A Study on the Education Service Quality for Overseas Students in Yunnan in the Context of Educational Internationalization; A Case Study of Southeast Asia and South Asian Countries [D]. Yunnan University, 2016,18-36.

[2] Tang Ying. A Study on Inter-cultural Adaptation of Overseas Students in China: A Case Study of University Overseas Students in Nanjing [D]. Nanjing University of Aeronautics and Astronautics, 2012,35-38.

[3] Nerguz Bulut Serin, Oguz Serin, L.Filiz Özbas. Predicting university students' life satisfaction by their anxiety and depression level [J]. Procedia Social and Behavioral Sciences, 2010,9(2):579-582.

[4] Nazmiye Civitci, Asım Civitci. Social Comparison Orientation, Hardiness and Life Satisfaction in Undergraduate Students [J]. Procedia-Social and Behavioral Sciences, 2015,( 25): 516-523.

[5] Muhammad Hilmy Muslim. An Examination of Leisure Participation, Family Assessment and Life Satisfaction in University Students [J]. Procedia-Social and Behavioral Science, 2015, (86): 58-63.

[6] Wang Xiaobing, Hu Qingqing. Liu Junxue's evaluation Market Theory of Higher Education Service [J]. Journal of Hunan University of Science and Technology (social science edition), $2014,31$.

[7] SHAKEEVA ANARA. A Study on Cross-cultural Adaptation of Kyrgyz Students in Guangzhou [D]. South China University of Technology, 2016,27-35.

[8] Chen Weiyan. Research on the Influence Mechanism of University Teachers' Work Performance from the Perspective of Psychological Capital [D]. China University of Mining and Technology, 2016,15-27.

[9] Elena Yu, Kosheleva, Amartey Josiah Amarnor and Ellina Chernobilsky. Stress Factors among International and Domestic Students in Russia[J]. Procedia-Social and Behavioral Sciences, 2015,200(6):460-466.

[10] Asim Civitci. Proposals for the Improvement of University Classrooms: the Perspective of Students with Disabilities[J]. Procedia-Social and Behavioral Sciences, 2016,(223): 175-182.

[11]Poturak, M."Private universities service quality and students satisfaction",[J]. Global business and economics research journal, 3(2): 122-125.

[12]Zhang Jie.Life satisfaction and its correlates among college students in China:A test of social reference theory[J].Asian Journal of Psychiatry,2014,10(6):215-219. 
[13] Muhamad Shah Kamal Ideris, Lim Ting Yi, Safarina Mohd Rodzi, Abd Rahim Romle, Mohd Akmal Hakim Mohamad Zabri and,Nor AzlindamazliniMahamad. Students' Satisfaction on Facilities in Universiti Utara Malaysia[J]. Hospitality and Environmental Management,2016, 34 (6): 795-800.

[14]Ilias, A., H.F.A. Hasan, R.A. Rahman and M.R. Yasoa. Student Satisfaction and Service Quality: Any Differences in Demographic Factors[J].International Business Research,2008, 1(4):131-143.

[15] Sun wenqing Research on the management status of students in xinjiang universities based on student satisfaction. [D]. Xinjiang normal university,2012. 32-45. 